\title{
Ação sistêmica e translaminar do óleo de nim visando ao controle de Tuta absoluta (Meyrick) (Lep.: Gelechiidae) em tomateiro
}

\author{
Systemic and translaminar action of neem oil for the \\ control of Tuta absoluta (Meyrick) (Lep.: Gelechiidae) in tomato
}

\author{
Aloisio Coelho Junior ${ }^{1 *}$, Francisco Carlos Deschamps ${ }^{2}$

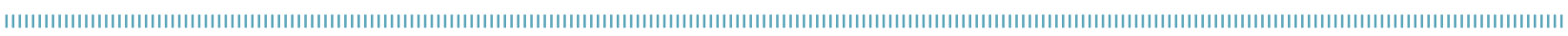

RESUMO: A traça Tuta absoluta (Meyrick) é o inseto-praga que mais compromete a produção do tomateiro. Basear o seu controle no uso de inseticidas sintéticos pode comprometer a cultura em termos econômicos e ambientais. Como alternativa de controle, o óleo de nim foi aplicado em folhas de tomateiro, avaliando os efeitos inseticida e antialimentar por ação sistêmica e translaminar. No ensaio para avaliar a ação translaminar, o óleo diluído em água foi aplicado na superfície adaxial dos folíolos, em concentraçóes de 0,5, 1, 5 e 10\%. A mortalidade observada variou entre 49 e $100 \%$, e o tamanho médio das minas, entre 1,62 e $0,34 \mathrm{~cm}$. Nos tratamentos representados por água e água + emulsificante (5\%), a mortalidade não ultrapassou $20 \%$, com tamanho médio das minas de $1,63 \mathrm{~cm}$. O estudo da ação sistêmica foi realizado ao aplicar o óleo de nim na superfície adaxial e abaxial de todas as folhas das plantas, à exceção daquelas em que as lagartas foram infestadas. Neste ensaio, o óleo foi aplicado nas concentraçôes de 1, 2,5 e 5\%, diluídos em água e emulsificante. Observou-se que a mortalidade foi maior que $90 \%$ quando o óleo foi aplicado nas concentraçôes de 2,5 e 5\%, sendo o tamanho médio das minas inferior a 1,0 cm. Não ocorreu mortalidade nos tratamentos controle, mas o tamanho das minas foi, em média, de 1,96 cm. Desta maneira ficou evidenciado que o óleo de nim apresenta efeito inseticida e antialimentar sobre lagartas de T. absoluta, com a propriedade de ser incorporado e translocado através das folhas de tomateiro.

PALAVRAS-CHAVE: plantas inseticidas; manejo integrado de pragas; traça-do-tomateiro.

\begin{abstract}
The leaf miner Tuta absoluta (Meyrick) is the pest that mostly jeopardizes tomato production. The use of synthetic pesticides for its control can affect the crop economically and environmentally. As an alternative form of control, neem oil was applied on tomato leaves in order to assess antifeedant and insecticidal effects by systemic and translaminar action. In experiment for translaminar action, oil diluted in water was applied to the adaxial surface of leaflets at concentrations of 0.5 , 1,5 and $10 \%$. The mortality rate ranged between 49 and $100 \%$, and the average size of the mines, between 1.62 and $0.34 \mathrm{~cm}$. In treatments represented by water and water + emulsifier (5\%), mortality did not surpass $20 \%$, with the average size of mines reaching $1.63 \mathrm{~cm}$. The study of systemic action was performed by applying neem oil to the adaxial and abaxial surfaces of all leaves, except those that were infested by caterpillars. In this assay, the oil was applied at concentrations of 1,2.5 and 5\%, being diluted in water and emulsifiers. We observed that the mortality rate exceeded $90 \%$ when the oil was applied at concentrations of 2.5 and $5 \%$, and the average size of mines was smaller than $1.0 \mathrm{~cm}$. There was no mortality in the control treatments, but the mine size was on average $1.96 \mathrm{~cm}$. Therefore, it is clear that the neem oil has an insecticidal and anti-food effect on T. absoluta caterpillars, and is possible to be incorporated and applied on tomato leaves.
\end{abstract}

KEYWORDS: insecticidal plants; integrated pest management; tomato leaf miner. 


\section{INTRODUÇÃO}

A traça, Tuta absoluta (Meyrick) (Lep.: Gelechiidae), destaca-se como um dos principais insetos-pragas que atacam o tomateiro (Solanum lycopersicum L.). Suas larvas minadoras alimentam-se do mesofilo foliar, flores, frutos e hastes, causando danos econômicos e facilitando a entrada de fitopatógenos e outros oportunistas (CAstelo Branco, 1992; Souza; ReIs, 1992).

Seu controle é realizado basicamente com o uso de inseticidas sintéticos, aplicados em até três pulverizaçôes semanais, as quais oneram o custo de produçáo. Outros efeitos decorrentes desta prática são os riscos de intoxicação aos aplicadores, ao meio ambiente, além da seleçấo de populaçôes resistentes e a eliminaçấo dos inimigos naturais (GUedes et al., 1994; Picanço et al., 1996).

De acordo com Vendramim; Castiglioni (2000), plantas inseticidas podem fazer parte das estratégias de controle alternativo de insetos-pragas. $\mathrm{O}$ nim, Azadirachta indica A. Juss. (Meliaceae), destaca-se pela eficiência no controle de artrópodes-pragas, apresentando baixa toxicidade a inimigos naturais e ao homem (Martinez, 2002). Vários produtos da planta de nim, como o óleo da semente, extratos aquosos e orgânicos, apresentaram efeitos bastante promissores para o controle de T. absoluta (TRINDADE et al., 2000; Souza; Vendramim, 2005; GonÇalves-Gervásio; VendRAMim, 2007).

O hábito minador das lagartas desta praga é um obstáculo ao uso de inseticidas naturais, uma vez que, no interior das minas, as lagartas ficam protegidas do contato direto com tais produtos. Gonçalves-Gervásio; Vendramim (2004) testaram o efeito de extratos de sementes de nim por ação de contato, sistêmica e translaminar. Os autores concluíram que os compostos inseticidas são capazes de penetrar o mesofilo foliar e, mesmo quando aplicados no solo, provocam níveis de mortalidade equiparados aos produtos aplicados diretamente sobre as lagartas. Martinez (2002) ressalta que a azadiractina, o principal ingrediente ativo do nim, atua de modo dose-dependente, podendo ter efeitos antialimentar e inibidor do crescimento com relaçáo ao tamanho e à idade do inseto.

Independentemente das características, origens e modo de ação dos inseticidas, seus efeitos sistêmico e translaminar são desejáveis quando destinados ao controle das lagartas de T. absoluta. Como o óleo de nim apresenta potencial para o controle deste inseto-praga, o objetivo do presente trabalho foi avaliar sua ação sistêmica e translaminar quando aplicado em folhas de tomateiro como estratégia de manejo integrado para o controle de lagartas de T. absoluta.

\section{MATERIAIS E MÉTODOS}

\section{Avaliação da ação translaminar do óleo de nim}

$\mathrm{O}$ ensaio foi realizado em casa de vegetação, com temperatura ambiente e iluminação natural. O óleo de nim comercial (Dalneen ${ }^{\circledR}$-Dalquim Ltda) foi testado em quatro concentraçôes $(0,5,1,5$ e $10 \%)$, diluído em água. Considerando que o óleo continha $5 \%$ de emulsificante, foi preparado um tratamento controle com 5\% de emulsificante diluído em água e outro contendo somente água. Todos os tratamentos foram aplicados com cinco repetiçóes, em delineamento experimental inteiramente casualizado. Cada repetição foi formada por uma planta de tomate, cultivar Santa Clara, com aproximadamente 20 dias de idade, cultivada em vaso com volume de $350 \mathrm{~mL}$ totalmente preenchido com substrato $\left(\right.$ Plantmax $^{\circledR}$ ). Para suprimento de água, os vasos foram colocados sobre uma garrafa plástica tipo PET de $2 \mathrm{~L}$, cortada pouco abaixo da metade, parcialmente preenchida com água. Para irrigar o substrato, adaptou-se um cordáo de algodáo com uma das extremidades inserida no fundo do vaso, e a outra mergulhada na água da garrafa PET. Em cada planta foi selecionada uma folha com cinco folíolos, a qual foi infestada com 10 lagartas recém-eclodidas. Após 24 horas, com o auxílio de um pincel, o óleo de nim foi aplicado na superfície adaxial dos folíolos que possuíam as minas, considerando que a penetração das lagartas realiza-se, preferencialmente, pela face abaxial das folhas (Imenes et al., 1990). Para impedir a fuga do inseto, cada folha foi protegida com uma bolsa de tecido (voil), presa ao pecíolo. Foram realizadas três avaliaçóes com intervalo de sete dias, sendo a primeira no sétimo dia após a inoculação das lagartas nas folhas. Este intervalo inicial foi escolhido com o intuito de não interferir na ação do óleo, considerando que os princípios ativos do nim permanecem atuantes por cerca de uma semana (StoKes; RedFern, 1982; SCHMUtTERER, 1990).

O efeito antialimentar foi avaliado com base no comprimento das minas, realizado com o auxílio de um paquímetro. O comprimento foi determinado sete dias após a inoculação das larvas, pela facilidade de observação das minas. Aos $14 \mathrm{e}$ 21 dias, o intercruzamento das minas não permitia medidas confiáveis. A mortalidade foi avaliada aos 21 dias pela dificuldade de analisar indivíduos mortos 7 e 14 dias após a inoculação das larvas.

\section{Avaliação da ação sistêmica via foliar}

O ensaio foi executado em laboratório, em temperatura média de $25 \pm 3^{\circ} \mathrm{C}$ e com iluminação natural. Para minimizar o efeito do fototropismo e a fotodegradação dos metabólitos do óleo, 
diariamente foi realizada uma troca entre as posiçóes dos vasos de tomateiro. Utilizou-se o óleo de nim comercial nas concentraçóes de 1, 2,5 e 5\%, diluídos em água, além dos tratamentos controle, mencionados na metodologia do ensaio anterior. Foram utilizadas cinco repetiçóes para cada concentração, constando de uma planta de tomate, cultivar Santa Clara, cultivada em um vaso de $350 \mathrm{~mL}$ com substrato (Plantmax ${ }^{\circledR}$ ) e o mesmo sistema de irrigação descrito anteriormente. Para avaliar o efeito sistêmico, dez lagartas foram inoculadas em uma folha com cinco folíolos, localizada na região mediana da planta. Esta folha não recebeu tratamento, enquanto as demais, localizadas acima e abaixo dela, foram pinceladas com o produto nas duas superfícies foliares. Os parâmetros estudados e os procedimentos gerais adotados foram os mesmos descritos no ensaio da ação translaminar.

\section{Análise estatística}

Os resultados de mortalidade e o tamanho médio das minas foram analisados quanto à normalidade e à homocedasticidade por meio dos testes de Shapiro-Wilk $\left(S A S^{\circledR}\right)$ e do teste de Hartley. Como os dados não corresponderam a essas pressuposiçóes do campo paramétrico, eles foram analisados por meio do teste não-paramétrico de Kruskall-Wallis (CAmpos, 1979).

\section{RESULTADOS E DISCUSSÃO}

\section{Ação translaminar}

Nas emulsóes preparadas com 1, 5 e $10 \%$ de óleo de nim comercial, a mortalidade foi de $100 \%$, enquanto na concentração de $0,5 \%$, (recomendada pelo fornecedor), a mortalidade foi de 49,4\% (Tabela 1). Já os tratamentos controle apresentaram baixa mortalidade $(7,8$ e 6,5\%). Os resultados apresentaram a mesma tendência daqueles descritos por

Tabela 1. Mortalidade (\%) ( \pm EP; erro padrão da média) de Tuta absoluta (Meyrick) determinada 21 dias após a inoculação das larvas e tamanho médio das minas $(\mathrm{cm})( \pm \mathrm{EP})$ determinado 7 dias após a inoculação das larvas, como resultado da ação translaminar de diferentes concentrações de óleo de nim.

\begin{tabular}{lcc} 
Tratamento & Mortalidade (\%) & Tamanho de Minas (cm) \\
\hline $10 \%$ & $100 \pm 0,0 \mathrm{a}$ & $0,34 \pm 0,01 \mathrm{a}$ \\
\hline $5 \%$ & $100 \pm 0,0 \mathrm{a}$ & $0,4 \pm 0,02 \mathrm{a}$ \\
\hline $1 \%$ & $100 \pm 0,0 \mathrm{a}$ & $0,53 \pm 0,02 \mathrm{ab}$ \\
\hline $0,5 \%$ & $49,38 \pm 5,9 \mathrm{ab}$ & $1,17 \pm 0,07 \mathrm{ab}$ \\
\hline Emulsificante 5\% & $7,8 \pm 3,3 \mathrm{~b}$ & $1,73 \pm 0,09 \mathrm{~b}$ \\
\hline Água & $6,5 \pm 4,1 \mathrm{~b}$ & $1,63 \pm 0,25 \mathrm{~b}$ \\
\hline
\end{tabular}

Médias seguidas da mesma letra na coluna não diferem entre si, pelo teste de Kruskall-Wallis a 5\% de probabilidade do erro.
Trindade et al. (2000), que relataram 100\% de mortalidade de lagartas de Tuta absoluta (Meyrick), utilizando extratos metanólicos de nim à 2, 4 e $8 \mathrm{~g} / \mathrm{L}$, com a mortalidade no grupo controle situando-se em 4\%. É interessante observar que a efetividade do produto se confirmou em diferentes extratos e modos de aplicação.

Os resultados de TRINDADE et al. (2000) foram gerados de forma diferente em relação ao presente trabalho, já que primeiramente foi aplicado o produto para depois inocular as lagartas. GonçALVEs-Gervásio; Vendramim (2007) relataram mortalidade superior a $90 \%$ para a ação translaminar de extratos aquosos de sementes de nim, comparados a 6\% no controle sobre as lagartas de T. absoluta. Souza; VendRAmim (2005) observaram a ação translaminar do óleo de nim em plantas de tomate sobre mosca-branca [Bemisia tabaci (Gennadius)]. Neste caso, a mortalidade relatada em dois ensaios conduzidos foi superior a $90 \%$ para o óleo de nim a 5\%. Esta tendência também foi descrita por VERKERK et al. (1998), estudando a ação translaminar de extratos de sementes de nim sobre os pulgóes Myzus persicae (Sulzer) e Brevicoryne brassicae (L.) na cultura do repolho. Pode-se observar que a ação translaminar do óleo de nim sobre a T. absoluta foi efetiva. Independentemente da forma de obtenção e aplicaçáo do ingrediente ativo do nim, a ação translaminar é dose-dependente. Neste caso, as emulsóes aplicadas devem conter concentraçóes acima de $1 \%$ do óleo de nim.

$\mathrm{O}$ estudo da ação translaminar de produtos destinados ao controle de T. absoluta é importante devido ao hábito das lagartas ao penetrarem preferencialmente pela face abaxial das folhas, formando minas no mesofilo (IMENEs et al., 1990). Neste local relativamente seguro, as lagartas se alojam até completarem seu ciclo larval e se transformarem em pupas. A propriedade que o óleo de nim apresenta, de transpor a epiderme das folhas, garante o efeito inseticida ou antialimentar deste produto. Além disso, o fato de o óleo de nim penetrar na folha possibilita maior proteção contra fatores ambientais que podem degradar os compostos inseticidas presentes no óleo (Souza; Vendramim, 2005).

Evidências de que o óleo de nim tem efeito antialimentar foram demonstradas quando o produto foi utilizado em concentraçóes acima de $0,5 \%$, com as lagartas migrando de sua mina original e buscando uma nova área para alimentação. Em todos os ensaios de ação translaminar, o tamanho médio das minas foi inversamente proporcional à concentração de óleo utilizada. Nos tratamentos a 5 e $10 \%$ de óleo, as minas não ultrapassaram $0,4 \mathrm{~cm}$, enquanto nos tratamentos controle, alcançaram tamanhos superiores a $1,6 \mathrm{~cm}$ (Tabela 1 ).

GonçAlves-Gervásio; Vendramim (2007) investigaram o efeito antialimentar para a ação translaminar de extrato aquoso de nim sobre T. absoluta. Porém, neste trabalho, os 
efeitos foram avaliados pela classificaçáo das minas em categorias, considerando-se pequenas as menores de $0,5 \mathrm{~cm}$, as médias, entre 0,5 e $1,0 \mathrm{~cm}$, e as grandes, maiores que $1,0 \mathrm{~cm}$. Mesmo assim, a tendência dos resultados foi semelhante, já que o tamanho médio das minas na concentração de 1 e $5 \%$ esteve sempre abaixo de $0,5 \mathrm{~cm}$, sendo consideradas pequenas pelo critério de GonçaLVEs-Gervásio; VendRAmim (2007). Estes resultados, quando comparados aos da testemunha água, servem de evidência para o elevado efeito antialimentar do óleo de nim.

\section{Ação sistêmica via foliar}

Considerando que o óleo de nim interfere na alimentação e na viabilidade larval de T. absoluta, por ação translaminar, buscou-se avaliar também seu efeito sistêmico. Desta forma, a aplicação seria facilitada, já que o produto poderia translocar-se para outras partes da planta. Alguns estudos comprovaram que é possível controlar a mosca-branca (B. tabaci), e até mesmo a T. absoluta, aplicando-se o óleo de nim ou solução aquosa no substrato de solo (Souza; Vendramim, 2005; Gonçalves-Gervásio; Vendramim, 2007). Isso sugere que o ingrediente ativo aplicado no solo pode agir na planta a partir de sua absorção pelas raízes. No presente trabalho, buscou-se avaliar a propriedade sistêmica do óleo de nim quando aplicado nas folhas, levando-se em consideração que a pulverização nas folhas é a principal forma de aplicação dos inseticidas nas plantas.

Conforme pode ser observado nos resultados apresentados na Tabela 2, o óleo de nim pode atuar de forma sistêmica, sendo seus efeitos dose-dependentes. Com 2,5\% de óleo de nim, a mortalidade das lagartas foi de $90 \%$ contra $30,88 \%$ para a concentraçáo de $1 \%$. Resultados semelhantes foram descritos por Souza; Vendramim (2005), que relataram $100 \%$ de mortalidade de ninfas de $B$. tabaci com dose de $50 \mathrm{~mL}$ de óleo de nim a 1, 5 e $10 \%$ aplicados no solo, ou ainda, mortalidade superior a $70 \%$ quando as doses foram de 30 e $20 \mathrm{~mL}$. Em ambos os experimentos, a mortalidade do controle (água) não ultrapassou $10 \%$. Gonçalves-Gervásio; Vendramim (2007) descreveram a

Tabela 2. Mortalidade (\%) ( \pm EP; erro padrão da média) de Tuta absoluta (Meyrick) determinada 21 dias após a inoculação das larvas e tamanho médio das minas $(\mathrm{cm})( \pm \mathrm{EP}$ ) determinado 7 dias após a inoculação das larvas, como resultado da ação sistêmica via foliar de diferentes concentrações de óleo de nim.

\begin{tabular}{lcc} 
Tratamento & Mortalidade (\%) & Tamanho de Minas (cm) \\
\hline $5 \%$ & $100 \pm 0,0 \mathrm{a}$ & $0,84 \pm 0,14 \mathrm{a}$ \\
\hline $2,5 \%$ & $90 \pm 10,0 \mathrm{a}$ & $0,98 \pm 0,04 \mathrm{ab}$ \\
\hline $1 \%$ & $30,88 \pm 8,1 \mathrm{ab}$ & $1,82 \pm 0,13 \mathrm{~b}$ \\
\hline Água & $0 \pm 0,0 \mathrm{~b}$ & $1,96 \pm 0,09 \mathrm{~b}$ \\
\hline
\end{tabular}

Médias seguidas da mesma letra na coluna não diferem entre si, pelo teste de Kruskall-Wallis a 5\% de probabilidade do erro. ação sistêmica de extrato aquoso de nim aplicado no solo, obtendo mortalidade superior a $80 \%$ para concentração de $1 \%$ e $100 \%$ para concentração de $10 \%$.

Parte da mortalidade observada com a ação sistêmica foliar do óleo de nim pode estar associada ao efeito antialimentar. Esta possibilidade está baseada na constatação de que o tamanho médio das minas para a concentração de 5\% não ultrapassou $0,9 \mathrm{~cm}$, enquanto para a concentração de $1 \%$ o controle foi superior a $1,8 \mathrm{~cm}$ (Tabela 2).

Gonçalves-Gervásio; Vendramim (2007), aplicando extratos aquosos de nim no solo para o controle de T. absoluta, também relataram que, em elevadas concentraçôes de 10,5 e $1 \%$, a porcentagem de minas menores que $0,5 \mathrm{~cm}$ foi maior que em baixas concentraçóes, onde as minas classificadas como "grandes" (maiores que $1,0 \mathrm{~cm}$ ) predominaram. Entretanto, isso não permite estabelecer claramente se o efeito antialimentar é decorrência direta do óleo de nim, mais precisamente da azadiractina - seu componente ativo - ou consequência do efeito tóxico sentido pelo inseto e manifestado na redução do consumo alimentar.

A concentração de nim nas emulsóes a serem aplicadas no controle dos insetos será determinada pela escolha do seu modo de ação. Em relação à açáo translaminar, ficou bem evidenciado no presente trabalho que a ação sistêmica do nim somente será efetiva se concentraçôes maiores forem utilizadas, em especial para obter $100 \%$ de mortalidade (Tabela 2). Isso pode estar relacionado à translocação do nim através dos tecidos vegetais, ou entâo à estimulaçấo dos mecanismos de proteçáo da planta contra o ataque dos insetos e outros agentes agressores.

\section{CONCLUSÕES}

O óleo de nim apresenta efeito inseticida e antialimentar sobre lagartas de Tuta absoluta. Também desloca-se de forma translaminar e sistêmica em folhas de tomateiro. A ação inseticida do óleo de nim sobre lagartas de T. absoluta, tanto por via sistêmica quanto translaminar, é dose-dependente quando aplicado em folhas de tomateiro. A açáo inseticida sistêmica via foliar do óleo de nim contra a T. absoluta em folhas de tomateiro ocorre com concentrações de 2,5\%, ao passo que a translaminar é eficaz em concentraçóes de $1 \%$.

\section{AGRADECIMENTOS}

Ao apoio financeiro oferecido pelo projeto Prodetab 77-01/01, por meio do convênio Embrapa/ Fundagro/ Epagri/ UFSC. 


\section{REFERÊNCIAS}

CAMPOS, H. Estatística experimental não-paramétrica. Piracicaba: Depto. de Matemática e Estatística da Escola Superior de Agricultura “Luiz de Queiroz", 1979. 343p.

CASTELO BRANCO, M. Flutuação populacional da traça-dotomateiro no Distrito Federal. Horticultura Brasileira, Vitória da Conquista, v.10, p.33-34, 1992.

GONÇALVES-GERVÁSIO, R.C.R.; VENDRAMIM, J.D. Modo de ação de extratos de meliáceas sobre Tuta absoluta (Meyrick, 1917) (Lepidoptera: Gelechiidae). Arquivos do Instituto Biológico, São Paulo, v.71, p.215-220, 2004.

GONÇALVES-GERVÁSIO, R.C.R.; VENDRAMIM, J.D. Bioatividade do extrato aquoso de nim sobre Tuta absoluta (MEYRICK, 1917) (Lepidóptera: Gelechiidae) em três formas de aplicação, Ciência e Agrotecnologia, Lavras, v.31, n. 1, p.28-34, 2007.

GUEDES, R.N.C. ; PICANÇO, M.C.; MATIOLI, A.L.; ROCHA, R.M. Efeito de inseticidas e sistemas de condução do tomateiro no controle de Tuta absoluta (Meyrick) (Lepdoptera: Gelechiidae). Anais da Sociedade Entomológica do Brasil, Piracicaba, v.23. p.321-325, 1994.

IMENES, S.D.L.; FERNANDES, M.A.U.; CAMPOS, T.B.; TAKEMATSU, A.P. Aspectos biologicos e comportamentais da traça do tomateiro Scrobipaupula absoluta (Meyrick, 1917), (Lepidoptera-Gelechiidae). Arquivos do Instituto Biológico, São Paulo, v.57, n. 1/2, p.63-68, 1990.

MARTINEZ, S.S. (ed.). O nim Azadirachta indica: natureza, usos múltiplos, produção. Londrina: Instituto Agronômico do Paraná, 2002. 142p.

PICANÇO, M.C.; GUEDES, R.N.C.; LEITE, G.L.D.; FONTES, P.C.R.; SILVA, E.A. Incidência de Scrobipalpuloides absoluta em tomateiro sob diferentes sistemas de tutoramento e de controle químico. Horticultura Brasileira, Vitória da Conquista, v.13, p.180-183, 1996.
SAS INSTITUTE. Statistical analysis system: getting started with the SAS learning, version 9.1. The United States: SAS Institute, Cary, 2009.

SCHMUTTERER, H. Properties and potential of natural pesticides from Nim tree, Azadirachta indica. Annual Review of Entomology, Palo Alto, v.35, p.271-297, 1990.

SOUZA, A.P.; VENDRAMIM, J.D. Efeito translaminar, sistêmico e de contato de extratos aquosos de sementes de nim sobre Bemisia tabaci (genn.) Biótipo B em tomateiro. Neotropical Entomology, Londrina, v.34, n. 1, 2005.

SOUZA, J.C. de.; REIS, P.R. (Ed.) Traça-do-tomateiro: Histórico reconhecimento, biologia, prejuízos e controle. Belo Horizonte: Epamig, 1992. (Boletim, 38).

STOKES, J.B.; REDFERN, R.E. Effect of sunlight on azadirachtin: antifeeding potency. Journal of Environmental Scientific Health, Fairfax, v.17, p.57-65, 1982.

TRINDADE, F.C.P.; MARQUES, I.M.R.; XAVIER, H.S.; OLIVEIRA, J.V. Extratos metanólicos da amêndoa da semente de nim e a mortalidade de traça-do-tomateiro, Scientia Agrícola, Santa Maria, v.57, n.3, p.407-413, 2000.

VENDRAMIM, J.D.; CASTIGLIONI, E. Aleloquímicos, resistência de plantas e plantas inseticidas. In: GUEDES, J.C; COSTA, I.D.; CASTIGLIONI, E. (eds.). Bases e Técnicas de Manejo de Insetos. Bases e Técnicas de Manejo de Insetos. Santa Maria: Pallotti, 2000, p.113-135.

VERKERK, R.H.J.; NEUGEBAUER, K.R.; ELLIS, P.R.; WRIGHT, D.J. Aphids on cabbage: tritrophic and selective insecticide interactions. Bulletin of Entomological Research, v.88, p.343349, 1998. 